Российской Федерации государственной инфраструктуры качества, заложенной в путь развития экономической политики.

Стоит заметить тот факт, что ситуация, происходящая в экономической сфере, а именно ускоренные темпы развития в связи с измененными способами общественного производства выявляют явно запоздалую и консервативную стандартизация в Российской Федерации в рамках современного времени. Поэтому считаю, что только углубленные научные изучения в области стандартизации помогут ей нагнать темпы отечественной экономики.

1. Логанина, В.И. Стандартизация и сертификация в строительстве: Учебное пособие / В.И. Логанина, О.В. Карпова, А.М. Степанов. - М.: БАСТЕТ, 2018. - 256 с.

2. Метрология. Стандартизация. Сертификация: Учебник / Под ред. В.М. Мишина. - М.: ЮНИТИ, 2017. - 495 с.

3. Мороз, В.Г. Метрология, стандартизация и сертификация / В.Г. Мороз, Л.М. Духовный, Г.Н. Туревич. - М.: МГИУ, 2018. - 78 с.

4. Николаева, М.А. Стандартизация, метрология и подтверждение соответствия: Учебник / М.А. Николаева, Л.В. Карташова. - М.: ИД ФОРУМ, НИЦ ИНФРА-М, 2013. - 336 с.

\title{
Кожемякина В.И. \\ Параметрическое изменение значений атрибутов элементов в ПО Tekla Structures средствами программы Grasshopper
}

Санкт-Петербургский государственный архитектурно-строительный университет (Россия, Санкт-Петербург)

doi: 10.18411/trnio-01-2022-13

\section{Аннотация}

В данной статье рассматривается способ параметрического пакетного изменения значений атрибутов элементов и узлов-компонентов в ПО Tekla Structures средствами программы Grasshopper. Показана возможность внесения изменений по определенной пользователем зависимости. Также проанализированы преимущества данного метода перед ручным вводом изменений в модель.

Ключевые слова: Tekla Structures, атритубы, Grasshopper, визуальное программирование, система автоматизированного проектирования, информационная модель здания, передача данных.

\section{Abstract}

This article deals with the method of parametric batch changing of element attributes in software Tekla Structures by Grasshopper. It is shown that there is possibility of making changes according to a user-defined dependency. The advantages of this method over manual import changes to the model are shown.

Keywords: Tekla Structures, attributes, Grasshopper, visual programming, computer-aided design system, building information model, data import.

С развитием информационных технологий автоматизация проектирования набирает всё большую популярность среди современных проектировщиков. Появление новых материалов в строительстве [1], необходимость усиления существующих конструкций [2] усиливает значимость программных комплексов в проектировании конструкций. Одним из средств автоматизации в данном случае является программа визуального программирования - Grasshopper. C её помощью можно как моделировать конструкции сложной нелинейной формы, так и выполнять рутинные задачи по внесению информации в модель. В данной статье описан способ пакетного изменений значений атрибутов элементов в ПО Tekla Structures по определенной пользователем зависимости. 


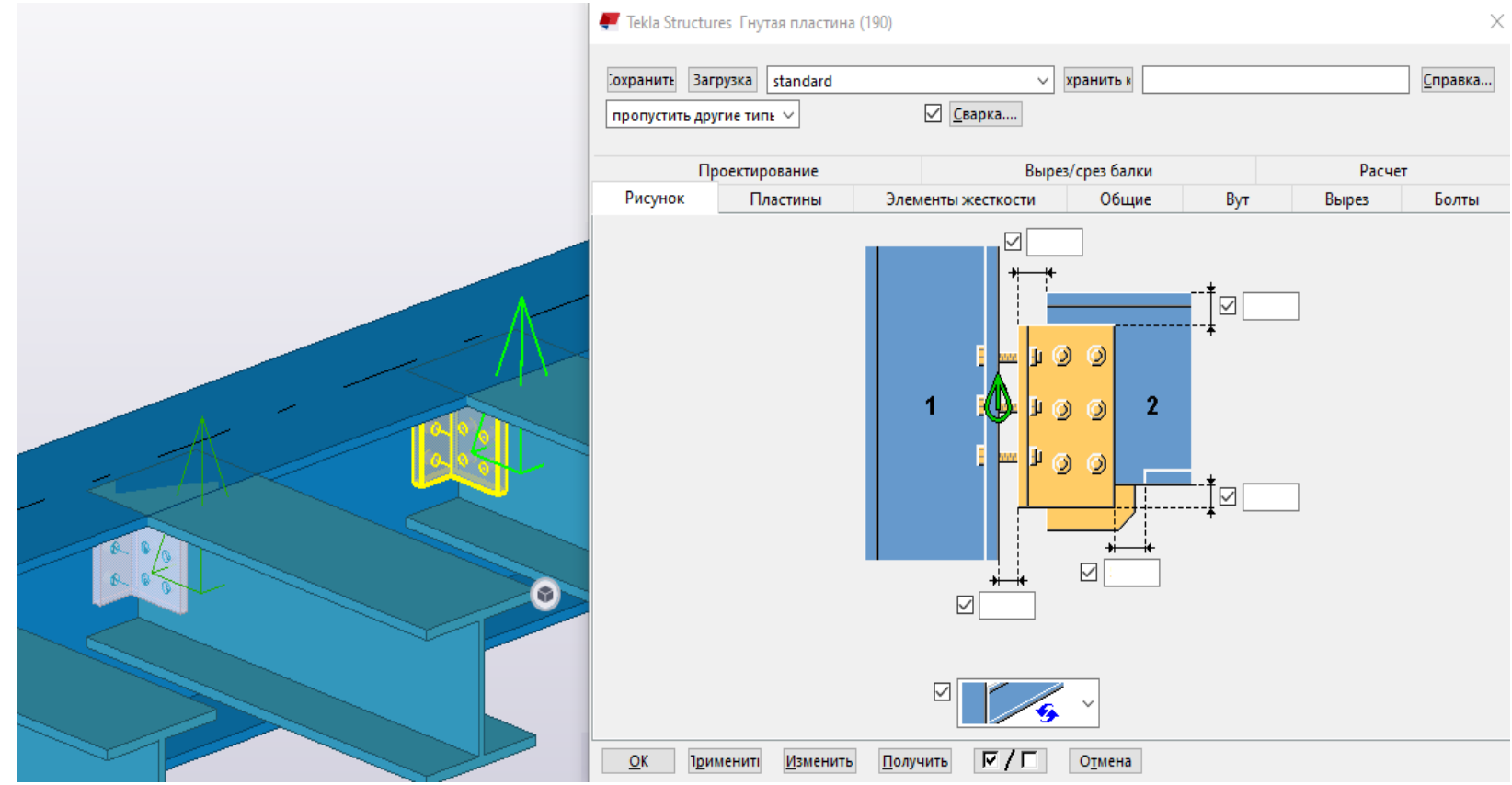

Рисунок 1. Значения атрибутов компонента по умолчанию

Каждый элемент модели в ПО Tekla Structures несет в себе информацию, заложенную пользователем в «атрибуты». Атрибуты в свою очередь напрямую влияют на элементы в модели - в них можно задать такие свойства как тип и размеры поперечного сечения элементов, их габариты, материал, количество болтов в узле, краевые расстояния в соединениях и т.д..

Программа визуального программирования Grasshopper позволяет менять значения атрибутов по определенной пользователем зависимости - в определенном порядке, или по сложному расчёту. Это позволяет снизить трудозатраты на выполнение рутинных операций, а также снижает риск ошибки при заполнении атрибутов.

Средствами управления в программе Grasshopper являются «ноды» или «узлы». Каждый из них выполняет особую операцию - определяет координаты точки, строит балку по двум точкам и т.П..

Для наглядного примера построим условную систему балок.

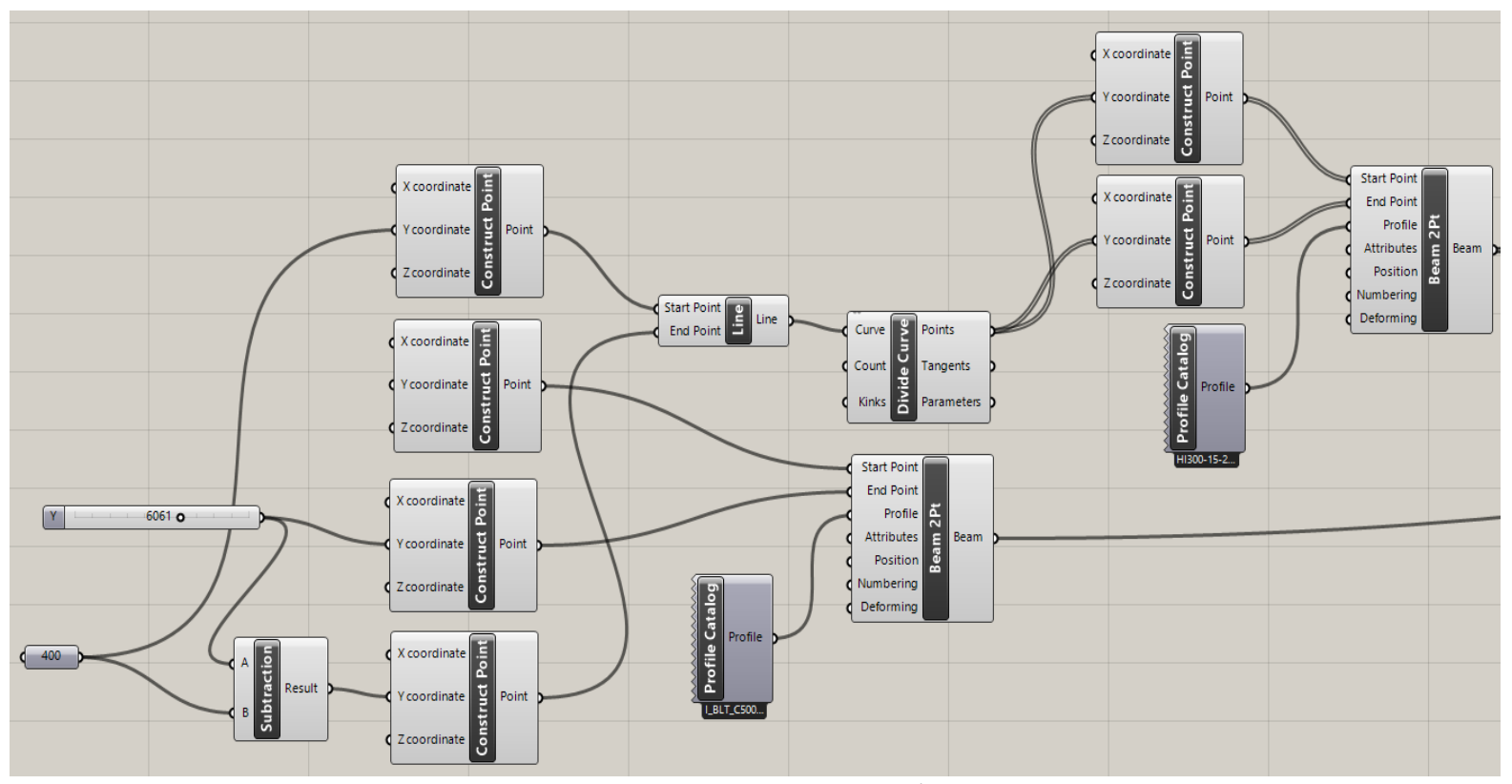

Рисунок 2. Алгоритм в Grasshopper 


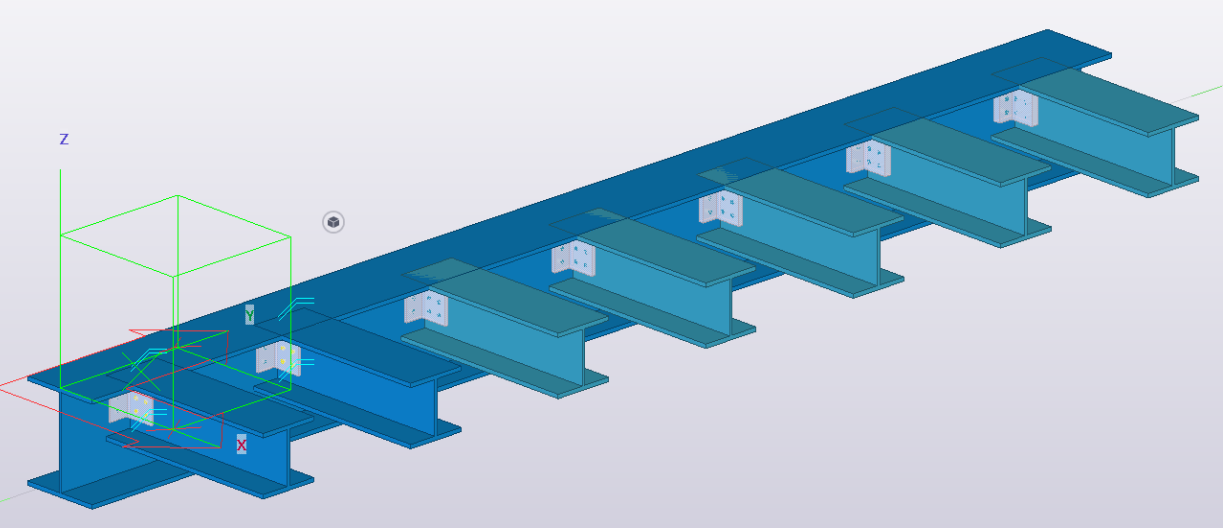

Рисунок 3. Полученная модель в Tekla Structures

В данной условной модели представлены главная балка, второстепенные балки и узлы опирания.

Поставим задачу изменить толщины пластин каждого узла в зависимости от величины изгибающего момента второстепенной балки.

C помощью плагина Grasshopper внесем условные значения (от 1 до 7) изгибающего момента в каждую из балок. Для этого нам необходимо знать название атрибута, отвечающего за величину изгибающего момента. Программные названия атрибутов к программе Tekla Structures определены в справочнике атрибутов [5]. В данном случае нам нужен атрибут moment1.

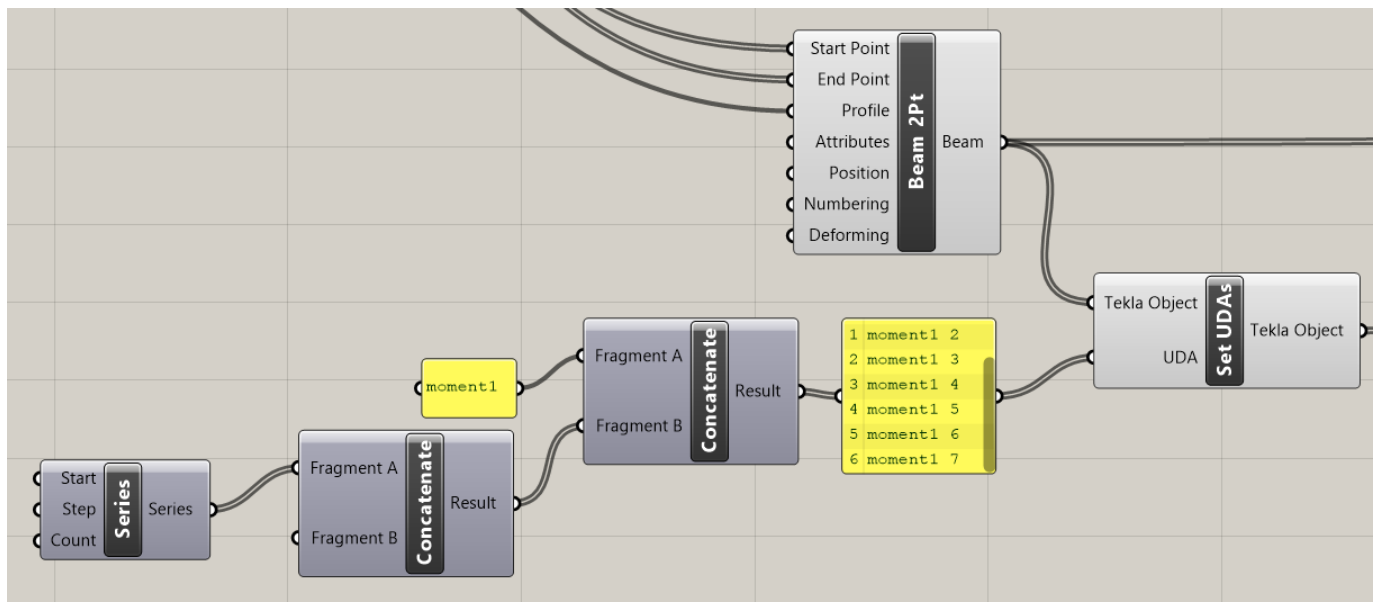

Рисунок 4. Внесение значений изгибающего момента

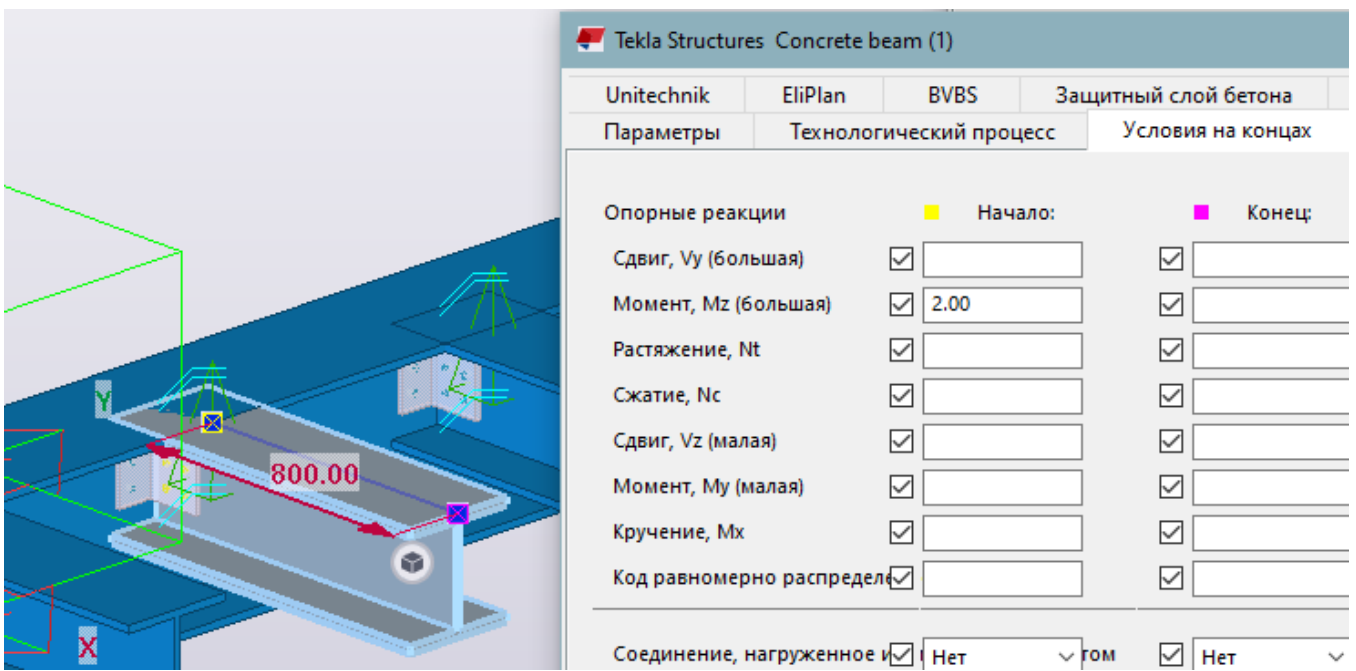

Рисунок 5. Значение атрибута момента после работы плагина 
Далее с помощью плагина Grasshopper в каждом узле-компоненте заполняем атрибут, отвечающий за толщину пластин. Перед этим изменим значение момента - умножим каждый на число $\mathrm{n}$, в данном случае $\mathrm{n}=5$.

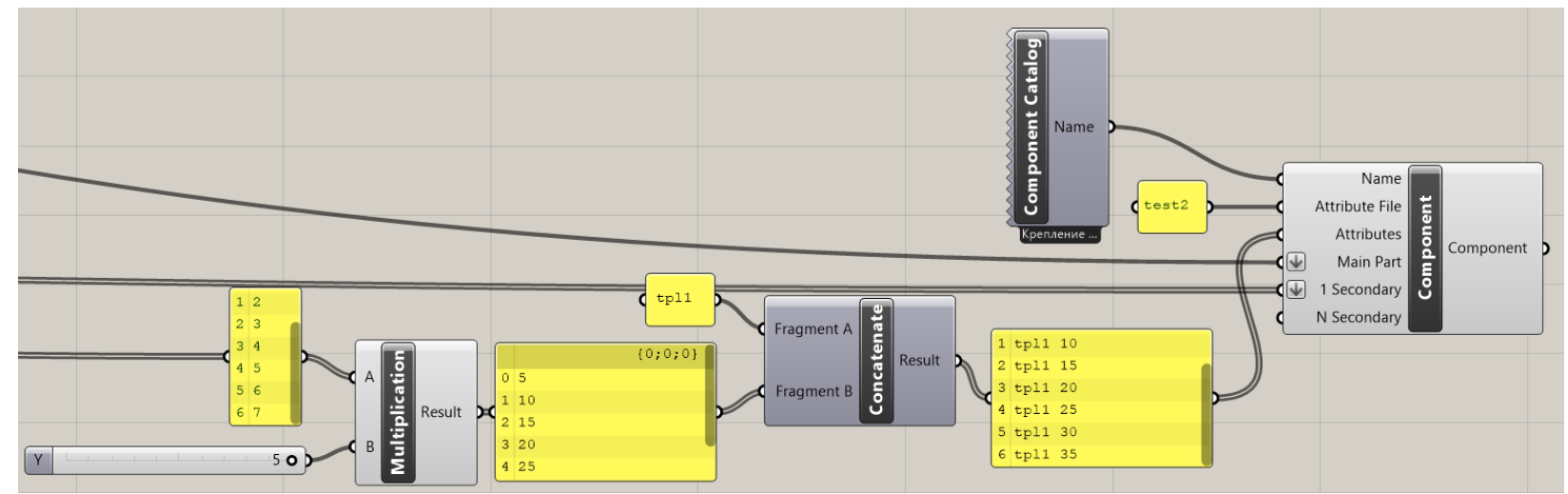

Рисунок 6. Импорт значений толщчины пластины в соединениях

Таким образом, толщина пластин каждого узла принимает значения от 5 мм до 35 мм.

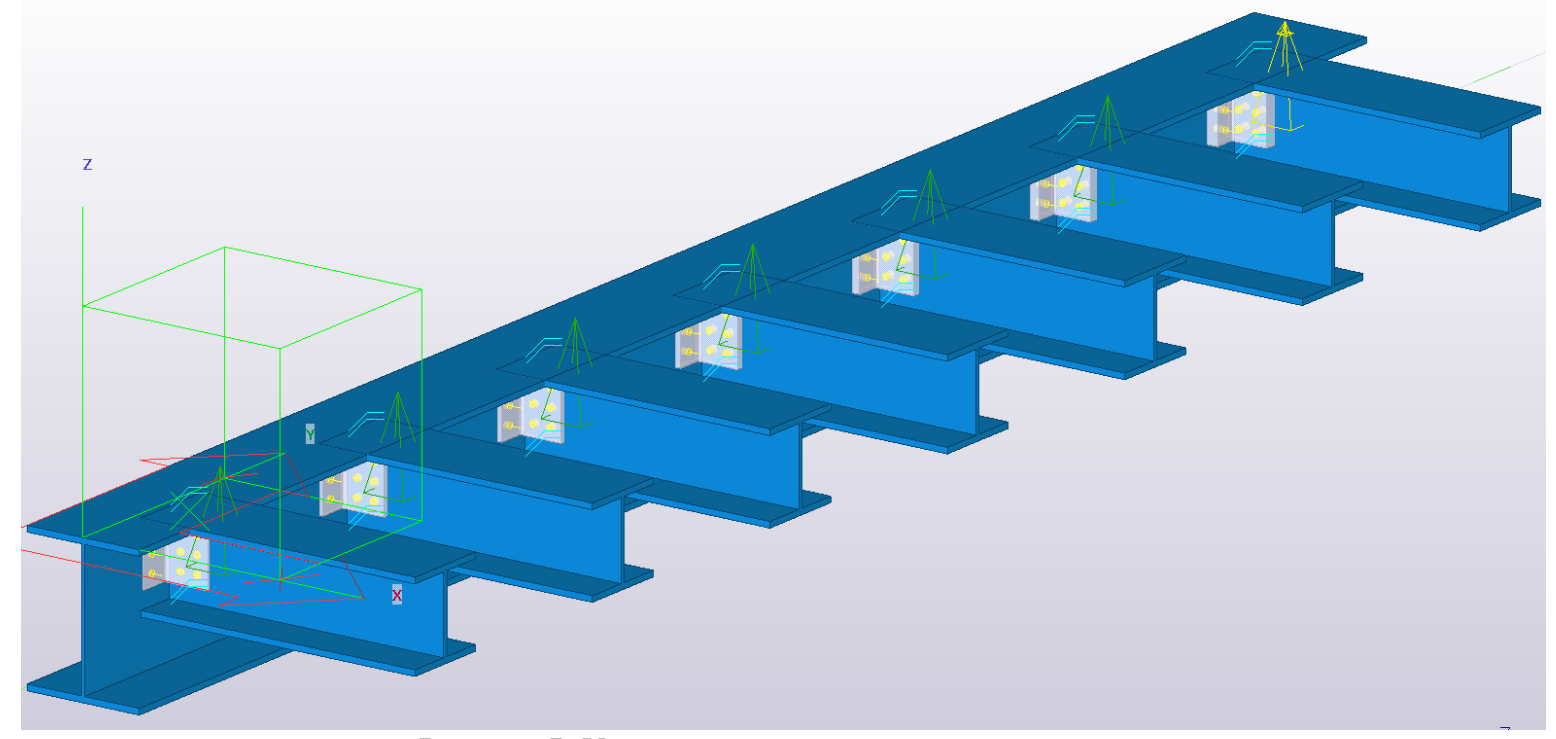

Рисунок 7. Узль с измененной толщиной пластин

Данный способ изменения значений атрибутов возможно комбинировать с расчетами - от простейших формул в Excel до аналогичной выгрузки данных из расчетных программ, таких как SCAD Office, LIRA, SAP2000, Robot Structural Analysis и т.д..

$$
* * *
$$

1. Миронова С.И., Нижегородцев Д. В. Скрытые особенности нового строительного материала. Материалы $74-$ ой научной конференции профессоров, преподавателей, научных работников, инженеров и аспирантов университета / СПбГАСУ. Архитектура-строительство-транспорт октябрь 2018 г. - СПб., 2018. - С. 23-29.

2. Серов Е.Н., Миронова С.И. Усиление клееных деревянных конструкций. «Вестник гражданских инженеров», 2018.- №5, стр. 68-74.

3. Совершенствование организации проектных работ путем внедрения технологий информационного моделиро/ вания [Электронный ресурс] / В. П. Грахов, С. А. Мохначев, П. Е. Манохин, А. Х. Иштряков // Современные проблемы науки и образования. - 2015. - № 1-1. - Режим доступа: https://cyberleninka.ru/article/n/

sovershenstvovanie/organizatsii/proektnyh/rabot/putem/vnedreniya/tehnologiy/informatsionnogo/modelirovaniya/ zdaniy.

4. Импорт значений пользовательских атрибутов [Электронный ресурс] Режим доступа: https://support.tekla.com/ru/doc/tekla-structures/2019i/int_attributes_importing

5. Tekla Structures Руководство по работе с шаблонами и отчетами ( 2010 Tekla Corporation 
6. Tekla Structures 2017 Справочник атрибутов шаблонов (C) 2017 Trimble

7. Абакумов Р.Г., Наумов А.Е., Зобова А.Г. Преимущества, инструменты и эффективность внедрения технологий информационного моделирования в строительстве // Вестник Белгородского государственного технологического университета им. В.Г. Шухова. 2017. №5. С. 171-181.

8. Zubin Khabazi. Generative algorithms using grasshopper; Journal, Morphogenesim. 2010. C. 48.

9. Xudong Wang. Rhinoceros parametric design and architecture; China, Information and computer. 2014.

10. Ying Wei, Haitao Zhao. Parametric design based on Rhino construction; China, Steel construction. 2014. C. 181.

\section{Ларионов П.Д., Рязанцева А.В., Усанова О.Ю. Очистка отходящих газов от оксидов азота и серы}

Московский политехнический университет (Россия, Москва)

doi: 10.18411/trnio-01-2022-14

\section{Аннотация}

В этой обзорной статье анализируются данные отечественной научной литературы за последние пять лет об основных методах, способах и оборудования для одновременного улавливания оксидов азота и оксидов серы на ТЭС.

Ключевые слова: оксид серы, оксид азота, адсорбенты, скрубберы, выбросы в атмосферу, улавливание оксидов.

\section{Abstract}

This review article analyzes the data of the domestic scientific literature over the past five years on the main methods, methods and equipment for simultaneous capture of nitrogen oxides and sulfur oxides at thermal power plants.

Keywords: sulfur oxide, nitric oxide, adsorbents, scrubbers, emissions into the atmosphere, capture of oxides.

Атмосферный воздух это одна из самых важных природных сред, обеспечивающих жизнь всему живому [1].

Он состоит из смеси различных газов и аэрозолей в приземном слое атмосферы.

В настоящее время в экологической ситуации в России происходит деградация окружающей природной среды. Обильное попадание в атмосферу загрязняющих веществ, вызывает нарушение её функций [2].

Интенсивность загрязнения атмосферного воздуха по регионам России, также зависит от таких факторов как урбанизированность региона, от промышленности региона, от применяемых технологий на производстве [3].

В настоящий момент, одним из приоритетных факторов в вопросе экологии атмосферного воздуха является, воздействие его на здоровье человека [4].

Основные загрязняющие вещества попадают в атмосферу в результате сжигания различных по структуре органических топлив, таких как, природный газ, уголь, нефть и другие, в результате работы различных теплоэнергетических установок, работы двигателей автомобильного, судоходного и авиационного транспорта, а также при различных технологических процессах производства [5-8].

Комплексное решение задач на предприятиях строительной индустрии позволит обеспечить высокую эффективность очистки воздуха и защиту атмосферы.

В результате создания и внедрения технологических процессов и оборудования, отвечающих требованиям научно-технического прогресса, а также ввода в действие новых эффективных материалов, достигается значительное сокращение вредных выбросов предприятиями промышленной индустрии. 